\title{
Comparative analysis of the efficacy and safety of modified FOLFOX-6 and DCF regimens as first-line treatment in advanced gastric cancer
}

\author{
ILHAN HACIBEKIROGLU ${ }^{1}$, HILMI KODAZ ${ }^{1}$, BULENT ERDOGAN ${ }^{1}$, ESMA TURKMEN $^{1}$, \\ ASIM ESENKAYA $^{2}$, YILMAZ ONAL ${ }^{3}$, SERNAZ UZUNOGLU $^{1}$ and IRFAN CICIN $^{1}$ \\ Departments of ${ }^{1}$ Medical Oncology, ${ }^{2}$ Radiology and ${ }^{3}$ Internal Medicine, Faculty of Medicine, \\ Trakya University, 22030 Edirne, Turkey
}

Received March 31, 2015; Accepted June 9, 2015

DOI: $10.3892 / \mathrm{mco} .2015 .592$

\begin{abstract}
The aim of this study was to retrospectively compare the efficacy and toxicity of the oxaliplatin +5 -fluorouracil $(5-\mathrm{FU})+$ leucovorin $(\mathrm{LV})$ regimen [modified $(\mathrm{m})$ FOLFOX-6] with that of the docetaxel + cisplatin + 5-FU regimen $(D C F)$ in patients with advanced gastric cancer (AGC). A total of 72 patients received DCF $\left(75 \mathrm{mg} / \mathrm{m}^{2}\right.$ docetaxel and $75 \mathrm{mg} / \mathrm{m}^{2}$ cisplatin on day 1 and $750 \mathrm{mg} / \mathrm{m}^{2}$ 5-FU on days 1-5) every 21 days, whereas 54 patients received mFOLFOX-6 (85 mg/m $\mathrm{m}^{2}$ oxaliplatin and $400 \mathrm{mg} / \mathrm{m}^{2} \mathrm{LV}$ as a 2-h infusion, followed by a 5 -FU bolus of $400 \mathrm{mg} / \mathrm{m}^{2}$ and $2,400 \mathrm{mg} / \mathrm{m}^{2} 5-\mathrm{FU}$ as a 46 -h continuous infusion) every 14 days. In the DCF arm, 55 (76.4\%) of the patients received prophylactic granulocyte colony-stimulating factor (G-CSF), 48-72 $\mathrm{h}$ following completion of chemotherapy. The median follow-up of the study was 12.1 months. The overall response rate (ORR) was $37.0 \%$ for mFOLFOX-6 and $40.3 \%$ for DCF $(\mathrm{P}=0.72)$. The median time to progression was 6.5 and 6.2 months in the mFOLFOX-6 and DCF arms, respectively $(\mathrm{P}=0.70)$. The median overall survival was 11.4 and 13.5 months in the mFOLFOX-6 and DCF arms, respectively $(\mathrm{P}=0.72)$. The rates of hematological toxicity did not differ between the two arms. However, in the subgroup analysis, grade 3-4 neutropenia and febrile neutropenia were significantly more common among patients who had not received G-CSF prophylaxis in the DCF arm. The incidence of grade 3-4 nausea/vomiting and diarrhea were significantly higher in the DCF arm. In conclusion, the present study demon-
\end{abstract}

Correspondence to: Dr Ilhan Hacibekiroglu, Department of Medical Oncology, Faculty of Medicine, Trakya University, 22030 Edirne, Turkey

E-mail: ilhanhbo@hotmail.com

Key words: docetaxel + cisplatin + 5-fluorouracil regimen, oxaliplatin + 5-fluorouracil + leucovorin regimen, gastric cancer, first-line strated that the efficacy of the mFOLFOX-6 regimen was comparable to that of the DCF regimen in AGC patients. In addition, the benefit of G-CSF prophylaxis in conjunction with the DCF regimen was demonstrated.

\section{Introduction}

Gastric cancer is one of the most common causes of cancer-related mortality worldwide (1). Despite the decline in incidence and mortality rates over the last two decades, $>40 \%$ of gastric cancer patients present with advanced-stage disease at diagnosis (2).

Several randomized trials demonstrated that palliative chemotherapy may relieve gastric cancer-related symptoms, prolong survival and improve the quality of life compared to best supportive care; therefore, it is offered as a routine treatment option to patients with a satisfactory performance status (3-5). A meta-analysis demonstrated that combination chemotherapy, particularly with three-drug combinations, is superior to monotherapy (6).

Since encouraging survival outcomes and better quality of life have been obtained with the docetaxel + cisplatin + 5-fluorouracil (5-FU) regimen (DCF) in several studies, this regimen has been widely used to treat advanced-stage gastric cancer $(7,8)$. However, these studies reported that the incidence of grade 3-4 toxicity with DCF was higher compared to that with other combination regimens; therefore, this regimen has not been established as standard chemotherapy for advanced gastric cancer (AGC).

Although a number of different chemotherapeutic agents have been tested in AGC patients, there is currently no globally accepted standard chemotherapeutic regimen for the treatment of AGC. In addition, despite the introduction of new-generation chemotherapeutic agents and the significant increase in the proportion of patients receiving palliative chemotherapy over the last few years, overall survival (OS) has not increased in AGC patients (9).

Thus, first-line chemotherapy should be extensively investigated in these patients, to determine the optimal chemotherapeutic regimens that will improve patient survival and quality of life, with reduced toxicity. 
In numerous phase II studies, combination chemotherapy with 5-FU, folinic acid (leucovorin; LV) and oxaliplatin (FOLFOX regimens), has exhibited considerable antitumor activity and a tolerable toxicity profile in AGC patients using different doses and schedules (10-14).

To address this issue, a retrospective analysis was conducted comparing baseline characteristics and treatment results with the oxaliplatin $+5-\mathrm{FU}+\mathrm{LV}$ regimen [modified (m)FOLFOX-6] and the DCF regimen in previously untreated patients with AGC.

\section{Patients and methods}

Patients. A total of 126 patients with AGC (unresectable or metastatic), who were treated with DCF or mFOLFOX-6 as first-line chemotherapy between June, 2010 and August, 2014 at the Department of Medical Oncology, Faculty of Medicine, Trakya University (Edirne, Turkey), were retrospectively reviewed. Patients who had received prior treatment, or exhibited insufficient hematological, hepatic and renal functions, were excluded from the analysis.

This retrospective study was approved by the Institutional Review Board of the Trakya University.

Treatment. In the DCF arm $(\mathrm{n}=72)$, the patients received $75 \mathrm{mg} / \mathrm{m}^{2}$ docetaxel and $75 \mathrm{mg} / \mathrm{m}^{2}$ cisplatin as an intravenous (i.v.) infusion on day 1 and $750 \mathrm{mg} / \mathrm{m}^{2} /$ day $5-\mathrm{FU}$ as a continuous infusion for 5 days. The DCF protocol was repeated every 3 weeks, for up to 6 cycles. In the DCF arm, 55 (76.4\%) of the patients received prophylactic granulocyte colony-stimulating factor (G-CSF) 48-72 h following completion of chemotherapy.

In the mFOLFOX6 arm $(n=54)$, the patients received $85 \mathrm{mg} / \mathrm{m}^{2}$ oxaliplatin and $400 \mathrm{mg} / \mathrm{m}^{2} \mathrm{LV}$ as an i.v. infusion over $2 \mathrm{~h}$ and a $5-\mathrm{FU}$ bolus of $400 \mathrm{mg} / \mathrm{m}^{2}$ as a $10-\mathrm{min}$ infusion, followed by $2,400 \mathrm{mg} / \mathrm{m}^{2} 5-\mathrm{FU}$ as a 46 -h continuous infusion. The mFOLFOX-6 protocol was repeated every 2 weeks, for up to 12 cycles. Chemotherapy was continued until disease progression, unacceptable toxicity, patient refusal or the physician's decision. Demographic, medical and toxicity data were obtained from the medical and chemotherapy charts.

The performance status of the patients was estimated according to the Eastern Cooperative Oncology Group performance status (ECOG PS; http://ecog-acrin.org/resources/ ecog-performance-status) scale.

Response to treatment. Response evaluation was performed every 8-12 weeks according to the Response Evaluation Criteria in Solid Tumors, version 1.1 (15) and the adverse events were graded according to the National Cancer Institute Common Terminology Criteria for Adverse Events, version 4.0 (16).

The time to progression (TTP) was measured from treatment initiation until the first evidence of disease progression. The OS was measured from treatment initiation until death or last control date. If a patient had succumbed to presumed progressive disease in the absence of radiographic evidence of progression, the date of death was used as the date of disease progression.

Statistical analysis. The baseline characteristics of the mFOLFOX-6 and DCF groups were compared by the $\chi^{2}$ test (for
Table I. Patient characteristics $(n=126)$.

\begin{tabular}{|c|c|c|c|}
\hline \multirow[b]{2}{*}{ Characteristics } & \multicolumn{2}{|c|}{ Chemotherapeutic regimen } & \multirow[b]{2}{*}{ P-value } \\
\hline & $\begin{array}{c}\text { mFOLFOX-6 } \\
\text { no. }(\%) \\
(\mathrm{n}=54)\end{array}$ & $\begin{array}{c}\mathrm{DCF}^{\mathrm{b}} \\
\text { no. }(\%) \\
(\mathrm{n}=72)\end{array}$ & \\
\hline Age (years) & & & 0.103 \\
\hline Median & 58.5 & 56.0 & \\
\hline Range & $32-80$ & $27-78$ & \\
\hline Gender & & & 0.590 \\
\hline Male & $42(77.8)$ & $53(73.6)$ & \\
\hline Female & $12(22.2)$ & $19(26.4)$ & \\
\hline ECOG PS & & & $<0.0001$ \\
\hline $0-1$ & $26(48.1)$ & $61(84.7)$ & \\
\hline 2 & $28(51.9)$ & $11(15.3)$ & \\
\hline Disease status & & & 0.700 \\
\hline Locally advanced & $3(10)$ & $2(7.1)$ & \\
\hline Metastatic & $27(90)$ & $26(92.9)$ & \\
\hline Radical gastrectomy & $13(24.1)$ & $19(26.4)$ & \\
\hline Any palliative surgery & $19(35.2)$ & $14(19.4)$ & \\
\hline Adjuvant treatment & & & 0.950 \\
\hline No & $41(75.9)$ & $55(76.4)$ & \\
\hline Yes & $13(24.1)$ & $17(23.6)$ & \\
\hline No. of metastatic sites & & & 0.720 \\
\hline Locally advanced & $5(9.3)$ & $4(5.6)$ & \\
\hline 1 & $31(57.4)$ & $44(61.1)$ & \\
\hline$\geq 2$ & $18(33.3)$ & $24(33.3)$ & \\
\hline \multicolumn{4}{|l|}{$\begin{array}{l}\text { Organs most } \\
\text { commonly involved }\end{array}$} \\
\hline Liver & $26(48.1)$ & $39(54.2)$ & 0.500 \\
\hline Peritoneum & $16(29.6)$ & $23(31.9)$ & 0.170 \\
\hline Lung & $17(31.5)$ & $15(20.8)$ & 0.780 \\
\hline $\begin{array}{l}\text { Presence of } \\
\text { ascites }\end{array}$ & $13(24.1)$ & $4(5.6)$ & 0.003 \\
\hline
\end{tabular}

${ }^{\mathrm{a}}$ Oxaliplatin + 5-FU + leucovorin. ${ }^{\mathrm{b}}$ Docetaxel + cisplatin + 5-FU ECOG PS, Eastern Cooperative Oncology Group performance status; 5-FU, 5-fluorouracil.

categorical variables) or the two-sample t-test (for continuous variables). The Kaplan-Meier method was used to provide median point estimates, TTP and median OS, and the confidence intervals (CIs) were calculated with the Greenwood's formula. The log-rank test was used to determine the statistical significance of the differences between the groups. Survival curves were created with IBM SPSS software, version 20.0 (IBM Corp., Armonk, NY, USA). Safety analyses were performed using descriptive statistics. $\mathrm{P}<0.05$ was considered to indicate statistically significant differences.

\section{Results}

Patient characteristics. A total of 126 patients were enrolled in this study, 54 and 72 of whom were treated with mFOLFOX-6 

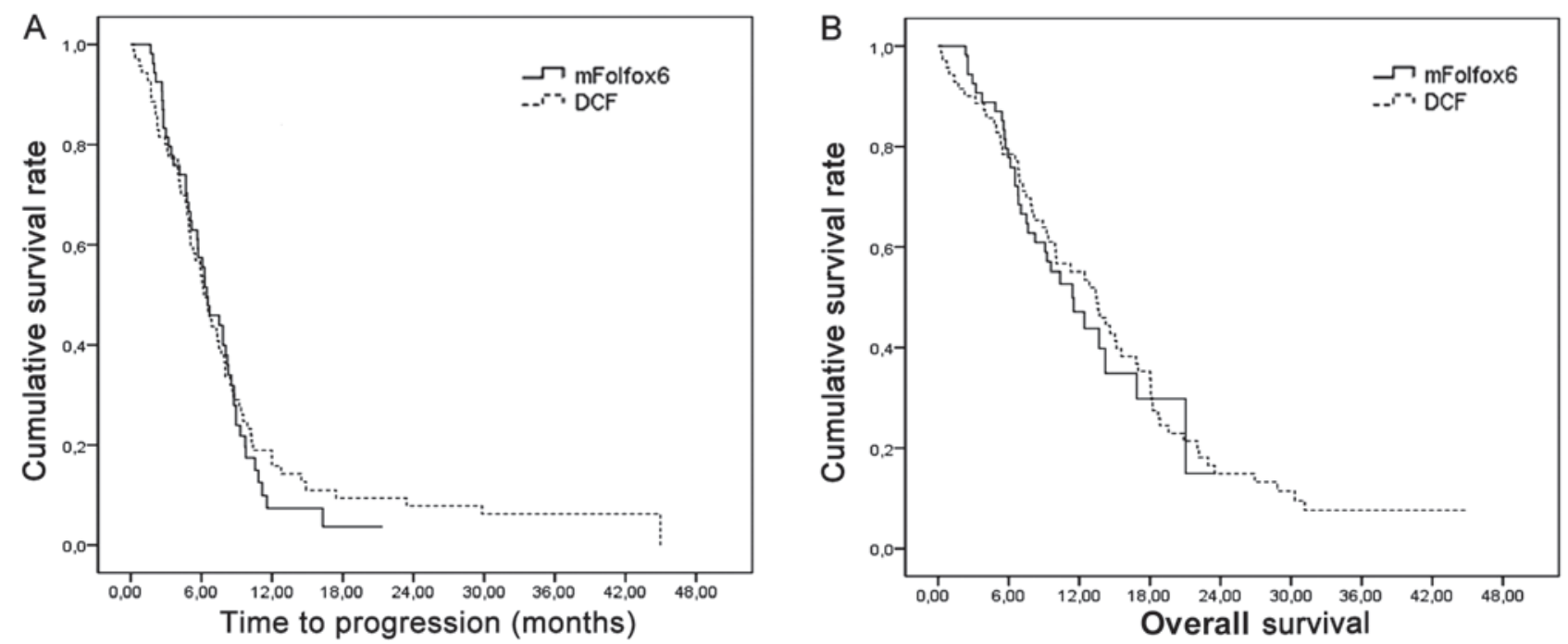

Figure 1. (A) Kaplan-Meier estimates of time to progression (TTP) according to chemotherapeutic regimen. The median TTP was 6.5 and 6.2 months in the oxaliplatin + 5-fluorouracil + leucovorin (mFOLFOX-6) and the docetaxel + cisplatin + 5-fluorouracil (DCF) arms, respectively (P>0.05). (B) Kaplan-Meier estimates of overall survival (OS) according to chemotherapeutic regimen. The median OS was 11.4 and 13.5 months in the mFOLFOX-6 and DCF arms, respectively $(\mathrm{P}>0.05)$.

Table II. Response to treatment according to chemotherapeutic regimen.

\begin{tabular}{|c|c|c|c|}
\hline \multirow[b]{2}{*}{ Characteristics } & \multicolumn{2}{|c|}{ Chemotherapeutic regimen } & \multirow[b]{2}{*}{ P-value } \\
\hline & $\begin{array}{c}\text { mFOLFOX-6a, } \\
\text { no. }(\%) \\
(\mathrm{n}=54)\end{array}$ & $\begin{array}{l}\mathrm{DCF}^{\mathrm{b}}, \\
\text { no. }(\%) \\
(\mathrm{n}=72)\end{array}$ & \\
\hline Complete response & $2(3.7)$ & $3(4.2)$ & 0.72 \\
\hline Partial response & $18(33.3)$ & $26(36.1)$ & \\
\hline Stable disease & $18(33.3)$ & $28(38.9)$ & \\
\hline Progressive disease & $16(29.7)$ & $15(20.8)$ & \\
\hline
\end{tabular}

${ }^{\mathrm{a}}$ Oxaliplatin + 5-FU + leucovorin. ${ }^{\mathrm{b}}$ Docetaxel + cisplatin + 5-FU. 5-FU, 5-fluorouracil.

and DCF, respectively. The median follow-up was 12.1 months and it was not significantly different between the two groups $(\mathrm{P}=0.08)$. According to the ECOG PS scale, $28(51.9 \%)$ of the patients in the mFOLFOX-6 arm and $11(15.3 \%)$ of the patients in the DCF arm had a PS of $2(\mathrm{P}<0.0001)$. The baseline characteristics of the patients according to the first-line regimen are summarized in Table I.

Response to treatment. Patients were treated with a median of 10 and 6 cycles of mFOLFOX- 6 and DCF, respectively.

The overall response rate (ORR) was 37.0 and $40.3 \%$ in the mFOLFOX-6 and DCF arms, respectively $(\mathrm{P}=0.72)$ (Table II). The median TTP was 6.5 (95\% CI: 4.8-8.1) and 6.2 (95\% CI: 5.2-7.2) months in the mFOLFOX-6 and DCF arms, respectively $(\mathrm{P}=0.70)$ and the median OS was 11.4 (95\% CI: 7.9-14.9) and 13.5 (95\% CI: 10.2-16.8) months in the mFOLFOX-6 and DCF arms, respectively $(\mathrm{P}=0.72)$ (Fig. 1).
Table III. Toxicities according to the NCI CTC 2.0. criteria.

\begin{tabular}{|c|c|c|c|}
\hline \multirow[b]{2}{*}{$\begin{array}{l}\text { Grade } 3-4 \\
\text { adverse events }\end{array}$} & \multicolumn{2}{|c|}{ Chemotherapeutic regimen } & \multirow[b]{2}{*}{ P-value } \\
\hline & $\begin{array}{c}\text { mFOLFOX-6a } \\
\text { no. }(\%) \\
(\mathrm{n}=54)\end{array}$ & $\begin{array}{l}\mathrm{DCF}^{\mathrm{b}}, \\
\text { no. }(\%) \\
(\mathrm{n}=72)\end{array}$ & \\
\hline \multicolumn{4}{|l|}{ Non-hematological } \\
\hline Nausea-vomiting & $4(7.4)$ & $15(20.8)$ & 0.037 \\
\hline Diarrhea & $3(5.6)$ & $14(19.4)$ & 0.024 \\
\hline Stomatitis & $4(7.4)$ & $11(15.3)$ & 0.180 \\
\hline Peripheral neuropathy & $3(5.6)$ & $3(4.2)$ & 0.710 \\
\hline \multicolumn{4}{|l|}{ Hematological } \\
\hline Neutropenia & $18(33.3)$ & $23(31.9)$ & 0.860 \\
\hline Febrile neutropenia & $1(1.9)$ & 7 (9.7) & 0.070 \\
\hline Anemia & $2(3.7)$ & $5(6.9)$ & 0.430 \\
\hline Thrombocytopenia & $3(5.6)$ & $5(6.9)$ & 0.750 \\
\hline
\end{tabular}

${ }^{\mathrm{a} O x a l i p l a t i n}+5-\mathrm{FU}+$ leucovorin. ${ }^{\mathrm{b}}$ Docetaxel + cisplatin +5 -FU. NCI-CTC, National Cancer Institute Common Toxicity Criteria. 5-FU, 5-fluorouracil.

Toxicities. The most commonly observed grade 3-4 hematological toxicity was neutropenia in both arms. The rate of grade 3-4 neutropenia did not differ significantly between the two arms (33.3\% in the mFOLFOX-6 arm vs. $31.9 \%$ in the $\mathrm{DCF}$ arm; $\mathrm{P}=0.860$ ). The rate of febrile neutropenia also did not differ significantly between the two arms $(1.9 \%$ in the mFOLFOX-6 arm vs. $9.7 \%$ in the DCF arm; $\mathrm{P}=0.07$ ).

However, in the DCF arm, 55 (76.4\%) of the patients received primary G-CSF prophylaxis subcutaneously for 5 days. In the subgroup analysis, the incidence of grade 3-4 neutropenia was significantly higher among patients in the DCF arm who had not received G-CSF prophylaxis (18.2 vs. $76.5 \%, \mathrm{P}<0.001)$. 
Febrile neutropenia was also significantly more common among patients in the DCF arm who had not received G-CSF prophylaxis (3.6 vs. $29.4 \%, \mathrm{P}=0.002$ ). The rates of anemia and thrombocytopenia were similar between the two arms.

The most commonly encountered grade 3-4 non-hematological toxicities were nausea/vomiting, mucositis and diarrhea in both arms. Grade 3-4 nausea-vomiting was more frequent with DCF (20.8\%) compared with mFOLFOX-6 (7.4\%) $(\mathrm{P}=0.037)$. Grade 3-4 diarrhea was also more frequent with DCF (19.4\%) compared with mFOLFOX-6 (5.6\%) $(\mathrm{P}=0.024)$. The treatment-related toxicities are summarized in Table III. Dose reduction was required in $15(27.8 \%)$ and 28 (38.9\%) patients in the mFOLFOX- 6 and DCF arms, respectively $(\mathrm{P}=0.19)$. Dose delays of at least 7 days were required in $15(27.8 \%)$ and $17(23.6 \%)$ patients in the mFOLFOX-6 and $\mathrm{DCF}$ arms, respectively $(\mathrm{P}=0.6)$. Treatment discontinuation due to toxicity was required in $2(3.7 \%)$ and $9(12.3 \%)$ patients in the mFOLFOX-6 and DCF arms, respectively $(\mathrm{P}=0.08)$. Treatment-related mortality was reported in $2(3.7 \%)$ and $4(5.6 \%)$ patients in the mFOLFOX-6 and DCF arms, respectively $(\mathrm{P}=0.62)$ (data not shown).

\section{Discussion}

Although AGC is considered to be relatively chemosensitive, systemic chemotherapy for patients with gastric cancer exerts a limited effect on OS. The majority of the patients have received palliative chemotherapy in recent years; however, OS did not increase as expected in patients with metastatic gastric cancer (9). In addition, there is currently no globally accepted chemotherapeutic regimen due to concerns regarding the toxicity of chemotherapy and the inconsistency in treatment response. In the face of the limited progress in the treatment options for $\mathrm{AGC}$, the therapeutic trend is toward improved clinical efficacy and a more acceptable toxicity profile.

Thus, we aimed to investigate the efficacy and safety of mFOLFOX-6 and DCF as first-line regimens in AGC. To the best of our knowledge, this study is the first to compare the efficacy and safety of these two regimens as the first-line treatment of $\mathrm{AGC}$ in the English literature.

In this study, we observed that DCF and mFOLFOX-6 were associated with similar ORR, TTP and OS, with a different toxicity profile in the first-line stetting for patients with AGC.

The DCF regimen has been widely used for the treatment of AGC, with encouraging survival outcomes and improved quality of life, as reported by several recent studies; in these studies, the ORR was reported to be $36.6-43 \%$, the TTP was 4.6-5.6 months and the OS was 9.2-10.4 months $(7,8,17)$. In the present study, the DCF regimen exhibited good efficacy, with an ORR of $40.3 \%$, a median TTP of 6.2 months and a median OS of 13.5 months. Thus, our efficacy results for the DCF arm were consistent with the literature.

Although DCF is commonly used in as first-line chemotherapy in metastatic gastric cancer worldwide, its tolerability is low due to toxicity. Therefore, evaluation of treatment benefits against chemotherapy-related toxicities is required and patients eligible for combination chemotherapy should be carefully selected.

In several trials, novel chemotherapeutic agents, such as capecitabine, taxanes, irinotecan and oxaliplatin, have been tested in AGC over the last few decades (18-20). In several studies conducted over the last decade, a number of different FOLFOX regimens have exhibited satisfactory clinical activity and acceptable toxicity in patients with AGC. The effectiveness of a variety of FOLFOX-6 regimens in the treatment of AGC has been recently evaluated, with a reported ORR of 40.2-48\% a TTP of 5.4-6.2 months and an OS of 8.6-13 months (11,21-25). In the present study, the mFOLFOX-6 regimen exhibited good efficacy, with an ORR of $37.0 \%$, a median TTP of 6.5 months and a median OS of 11.4 months. The results of the present study were similar to those previously reported by studies investigating FOLFOX-6 (11,21-25).

In terms of results, there was no significant difference between the DCF and mFOLFOX-6 arms; the ORR and efficacy data were comparable to the results of previous studies investigating the DCF and mFOLFOX regimens (7,8,17,21-25).

As regards toxicity, the two regimens were associated with a manageable toxicity profile. In the DCF arm, the incidence of grade 3-4 nausea/vomiting and diarrhea was significantly higher compared with that in the mFOLFOX-6 arm. The rate of grade 3-4 neutropenia was similar between the two arms. The lower hematological toxicity rates in the DCF arm of this study may be explained by $76.4 \%$ of the patients in the DCF arm receiving primary G-CSF prophylaxis. In the V325 trial, the rates of grade 3-4 neutropenia and febrile neutropenia were reported to be 82 and 29\%, respectively (7). In the subgroup analysis of the present study, grade 3-4 neutropenia and febrile neutropenia were significantly more common among patients in the DCF arm not receiving primary G-CSF prophylaxis; our results were similar to those of the V325 study.

The benefits of administering primary G-CSF prophylaxis in conjunction with docetaxel-based chemotherapy have been reported by phase 3 trials in breast cancer patients. When comparing patients receiving docetaxel-based combination regimens, a significant reduction in the incidence of febrile neutropenia and other neutropenia-related complications was observed in patients receiving docetaxel-based combination regimens with primary prophylactic G-CSF $(26,27)$. Recent European and American guidelines recommend the routine use of primary prophylaxis with G-CSF when using chemotherapeutic regimens associated with a risk of febrile neutropenia of $\geq 20 \%$, such as DCF $(28,29)$. The results of the V325 trial support the use of G-CSF in conjunction with the DCF protocol (7). In previous studies using FOLFOX-6 regimens for AGC, the rates of neutropenia, anemia and thrombocytopenia were 4.9-34.1, 1.2-20 and 0-7.3\% respectively (21-25). The incidence of grade 3-4 adverse effects in the mFOLFOX-6 arm was similar to that reported by previous studies. Dose reduction, dose delays and treatment-related mortality was similar between the two arms.

This study had certain limitations due to the indirect comparison and retrospective design. First, the proportion of patients with an ECOG PS of 2 was significantly higher in the mFOLFOX-6 arm, although PS is not an accurate criterion for evaluating the general status of cancer patients. However, our results suggest that the mFOLFOX-6 regimen is an efficient and tolerable treatment option for AGC patients with an ECOG PS of 2. Second, adverse event data were limited to grade 3-4 toxicities. We were unable to compare grade 1-2 toxicities due to insufficient records in the medical charts. Finally, there was heterogeneity in the DCF 
arm in terms of primary prophylaxis due to the physician's decision. However, despite these limitations, the results of this study may be considered as a major reference regarding the benefits of $\mathrm{G}-\mathrm{CSF}$ use in conjunction with the DCF regimen.

In conclusion, there was no statistically significant difference between the DCF and mFOLFOX-6 arms in terms of treatment results. The present study demonstrated that the efficacy of mFOLFOX-6 was comparable to that of DCF in AGC patients and the toxicity analysis revealed that DCF was associated with worse non-hematological toxicities. Therefore, the mFOLFOX-6 regimen may be an effective and tolerable treatment option for AGC patients with an ECOG PS of 2.

\section{References}

1. Ferlay J, Soerjomataram I, Dikshit R, Eser S, Mathers C, Rebelo M, Parkin DM, Forman D and Bray F: Cancer incidence and mortality worldwide: Sources, methods and major patterns in GLOBOCAN 2012. Int J Cancer 136: E359-E386, 2015.

2. Siegel R, Ma J, Zou Z and Jemal A: Cancer statistics, 2014. CA Cancer J Clin 64: 9-29, 2014.

3. Glimelius B, Ekström K, Hoffman K, et al: Randomized comparison between chemotherapy plus best supportive care with best supportive care in advanced gastric cancer. Ann Oncol 8: 163-168, 1997

4. Murad AM, Santiago FF, Petroianu A, Rocha PR, Rodrigues MA and Rausch M: Modified therapy with 5-fluorouracil, doxorubicin, and methotrexate in advanced gastric cancer. Cancer 72: 37-41, 1993.

5. Pyrhönen S, Kuitunen T, Nyandoto P and Kouri M: Randomised comparison of fluorouracil, epidoxorubicin and methotrexate (FEMTX) plus supportive care with supportive care alone in patients with non-resectable gastric cancer. Br J Cancer 71: 587-591, 1995

6. Wagner AD, Grothe W, Haerting J, Kleber G, Grothey A and Fleig WE: Chemotherapy in advanced gastric cancer: A systematic review and meta-analysis based on aggregate data. J Clin Oncol 24: 2903-2909, 2006.

7. Van Cutsem E, Moiseyenko VM, Tjulandin S, et al; V325 Study Group: Phase III study of docetaxel and cisplatin plus fluorouracil compared with cisplatin and fluorouracil as first-line therapy for advanced gastric cancer: A report of the V325 Study Group. J Clin Oncol 24: 4991-4997, 2006.

8. Roth AD, Fazio N, Stupp R, et al; Swiss Group for Clinical Cancer Research: Docetaxel, cisplatin, and fluorouracil; docetaxel and cisplatin; and epirubicin, cisplatin, and fluorouracil as systemic treatment for advanced gastric carcinoma: A randomized phase II trial of the Swiss Group for Clinical Cancer Research. J Clin Oncol 25: 3217-3223, 2007.

9. Bernards N, Creemers GJ, Nieuwenhuijzen GA, Bosscha K, Pruijt JF and Lemmens VE: No improvement in median survival for patients with metastatic gastric cancer despite increased use of chemotherapy. Ann Oncol 24: 3056-3060, 2013.

10. Lordick F, Lorenzen S, Stollfuss J, et al: Phase II study of weekly oxaliplatin plus infusional fluorouracil and folinic acid (FUFOX regimen) as first-line treatment in metastatic gastric cancer. $\mathrm{Br} \mathrm{J}$ Cancer 93: 190-194, 2005.

11. Al-Batran SE, Atmaca A, Hegewisch-Becker S, et al: Phase II trial of biweekly infusional fluorouracil, folinic acid, and oxaliplatin in patients with advanced gastric cancer. J Clin Oncol 22: 658-663, 2004

12. Yeh YS, Tsai HL, Ma CJ, Wu DC, Lu CY, Wu IC, Hou MF and Wang JY: A retrospective study of the safety and efficacy of a first-line treatment with modified FOLFOX-4 in unresectable advanced or recurrent gastric cancer patients. Chemotherapy 58: 411-418, 2012.

13. De Vita F, Orditura M, Matano E, et al: A phase II study of biweekly oxaliplatin plus infusional 5-fluorouracil and folinic acid (FOLFOX-4) as first-line treatment of advanced gastric cancer patients. Br J Cancer 92: 1644-1649, 2005.

14. Chao Y, Yeh KH, Chang CJ, Chen LT, Chao TY, Wu MF, Chang CS, Chang JY, Chung CY, Kao WY, et al: Phase II study of weekly oxaliplatin and 24-h infusion of high-dose 5-fluorouracil and folinic acid in the treatment of advanced gastric cancer. $\mathrm{Br}$ J Cancer 91: 453-458, 2004.
15. Eisenhauer EA, Therasse P, Bogaerts J, et al: New response evaluation criteria in solid tumours: Revised RECIST guideline (version 1.1). Eur J Cancer 45: 228-247, 2009.

16. Cirillo M, Venturini M, Ciccarelli L, Coati F, Bortolami O and Verlato G: Clinician versus nurse symptom reporting using the National Cancer Institute-Common Terminology Criteria for Adverse Events during chemotherapy: Results of a comparison based on patient's self-reported questionnaire. Ann Oncol 20: 1929-1935, 2009.

17. Ajani JA, Fodor MB, Tjulandin SA, Moiseyenko VM, Chao Y, Cabral Filho S, Majlis A, Assadourian S and Van Cutsem E: Phase II multi-institutional randomized trial of docetaxel plus cisplatin with or without fluorouracil in patients with untreated, advanced gastric, or gastroesophageal adenocarcinoma. J Clin Oncol 23: 5660-5667, 2005 .

18. Cunningham D, Starling N, Rao S, Iveson T, Nicolson M, Coxon F, Middleton G, Daniel F, Oates J and Norman AR; Upper Gastrointestinal Clinical Studies Group of the National Cancer Research Institute of the United Kingdom: Capecitabine and oxaliplatin for advanced esophagogastric cancer. N Engl J Med 358: 36-46, 2008.

19. Koizumi W, Narahara H, Hara T, et al: S-1 plus cisplatin versus $\mathrm{S}-1$ alone for first-line treatment of advanced gastric cancer (SPIRITS trial): A phase III trial. Lancet Oncol 9: 215-221, 2008.

20. Moehler M, Kanzler S, Geissler M, Raedle J, Ebert MP, Daum S, Flieger D, Seufferlein T, Galle PR and Hoehler T; Arbeitsgemeinschaft Internistische Onkologie, Germany: A randomized multicenter phase II study comparing capecitabine with irinotecan or cisplatin in metastatic adenocarcinoma of the stomach or esophagogastric junction. Ann Oncol 21: 71-77, 2010.

21. Luo HY, Xu RH, Zhang L, et al: A pilot study of oxaliplatin, fluorouracil and folinic acid (FOLFOX-6) as first-line chemotherapy in advanced or recurrent gastric cancer. Chemotherapy 54: 228-235, 2008

22. Lee HH, Hur H, Kim SH, Park AR, Kim W and Jeon HM: Outcomes of modified FOLFOX-6 as first line treatment in patients with advanced gastric cancer in a single institution; retrospective analysis. Cancer Res Treat 42: 18-23, 2010.

23. Louvet C, André T, Tigaud JM, et al: Phase II study of oxaliplatin, fluorouracil, and folinic acid in locally advanced or metastatic gastric cancer patients. J Clin Oncol 20: 4543-4548, 2002.

24. Cavanna L, Artioli F, Codignola C, et al: Oxaliplatin in combination with 5-fluorouracil (5-FU) and leucovorin (LV) in patients with metastatic gastric cancer (MGC). Am J Clin Oncol 29: 371-375, 2006.

25. Hwang WS, Chao TY, Lin SF, Chung CY, Chiu CF, Chang YF, Chen PM and Chiou TJ: Phase II study of oxaliplatin in combination with continuous infusion of 5-fluorouracil/leucovorin as first-line chemotherapy in patients with advanced gastric cancer. Anticancer Drugs 19: 283-288, 2008.

26. Vogel CL, Wojtukiewicz MZ, Carroll RR, Tjulandin SA, Barajas-Figueroa LJ, Wiens BL, Neumann TA and Schwartzberg LS: First and subsequent cycle use of pegfilgrastim prevents febrile neutropenia in patients with breast cancer: A multicenter, double-blind, placebo-controlled phase III study. J Clin Oncol 23: 1178-1184, 2005.

27. Martín M, Lluch A, Seguí MA, et al: Toxicity and health-related quality of life in breast cancer patients receiving adjuvant docetaxel, doxorubicin, cyclophosphamide (TAC) or 5-fluorouracil, doxorubicin and cyclophosphamide (FAC): Impact of adding primary prophylactic granulocyte-colony stimulating factor to the TAC regimen. Ann Oncol 17: 1205-1212, 2006.

28. Aapro MS, Cameron DA, Pettengell R, et al; European Organisation for Research and Treatment of Cancer (EORTC) Granulocyte Colony-Stimulating Factor (G-CSF) Guidelines Working Party: EORTC guidelines for the use of granulocyte colony-stimulating factor to reduce the incidence of chemotherapy-induced febrile neutropenia in adult patients with lymphomas and solid tumours. Eur J Cancer 42: 2433-2453, 2006.

29. National Comprehensive Cancer Network. Practice Guidelines in Oncology: Myeloid growth factors. V.I. 2014. http://www.nccn.org/professionals/physician_gls/pdf/myeloid_ growth.pdf. Accessed December 20, 2014. 